\title{
LIVROS
}

\section{PSICOLOGÍA DE LA OPRESIÓN. GUÍA PARA TERAPEUTAS Y ACTIVISTAS, 2008}

\author{
Philip Lichtenberg \\ (Editorial Cuatro Vientos, Chile)
}

Presentación - Donde hay desigualdad hay opresión. Las dinámicas opresivas dificultan y distorsionan las relaciones interpersonales en todos los ámbitos donde interactúan personas, desde la pareja hasta las organizaciones, empresas y naciones. Hoy, en la ciudadanía hay dos tendencias comunes y peligrosas: la tendencia a retirarse de la vida política y toda su complejidad, y el deseo de que otros lleven adelante nuestros puntos de vista de una manera eficaz. La apatía de muchos se ve apareada con la esperanza en un salvador idealizado. Sin embargo, como nos mostrara Paul Goodman, así como existe la psicoterapia que se aboca a perturbaciones neuróticas del individuo, también hay terapia para las instituciones sociales opresivas y anormales: la política. Uno de los temas centrales de este libro es la psicodinámica del conocido fenómeno de "identificación con el agresor", visto desde la perspectiva de Ferenczi, siguiendo con una aplicación del modelo gestáltico con su noción de límites de contacto y la identificación/proyección como un ajuste creativo a una situación, que de otra manera sería intolerable. Lichtenberg innova al introducir la fenomenología de la vivencia del opresor, al campo del nudo opresor/oprimido - que para su disolución requiere que se consideren las experiencias subjetivas del opresor-, la base del satyagraha de la no violencia de Gandhi y Martin Luther King. Un aporte a todos aquellos que con formación en ciencias sociales y políticas, o sin ella, quieran convertirse en agentes de cambio eficaces y humanitarios en la encrucijada de cada día. Una invitación a los ciudadanos a asimilar y entender nuestra sensación de vulnerabilidad e impotencia ante los procesos sociales, empoderándonos como sujetos de derecho, sin caer en pautas de dominación-sumisión.

El Autor - Después de doctorarse en psicología en Case Western Reserve University en 1952, trabajó los siguientes diez años como investigador en Harvard, en New York University y en el Hospital Michael Reese. Durante los siguientes 35 años fue profesor titular en Bryn Mawr College, donde actualmente es profesor emérito. Allí enseñó teoría de la personalidad, teoría social (incluyendo las ideas de Paolo Freire) y Gestalt; actualmente es profe- sor emérito. Se formó como terapeuta gestalt con Irving y Miriam Polster e Isadore From. Desde hace muchos años co-dirige el Instituto Gestalt de Filadelfia, donde participa en supervisiones de psicoterapias y en cursos de formación. Retirado desde 2002 y conocido por sus ideas de izquierda y su interés por los problemas sociales, es invitado frecuentemente por numerosos centros gestálticos de las Américas y Europa a dictar cursos y conferencias. Ha publicado seis libros además de numerosos artículos especializados.

Editorial: Editorial Cuatrocientos, Chile (http://www. cuatrovientos.cl)

Dirección: Maturana 19, Metro República, entre Brasil y Cumming. Santiago (Centro).

Teléfonos: (56 2) 6729226 / 695 4477. Fax: (56 2) 673 2153 